\title{
TECNOLOGÍAS DE INTERNET \\ (DE ARPANET A LA 3G)
}

\section{Gustavo López Rubio*}

A pesar de que Internet es una herramienta ampliamente utilizada, su conocimiento técnico queda reducido a ingenieros y profesionales de telecomunicación y tecnologías de información. Por eso, su funcionamiento, "grosso modo", supone una gran laguna para la mayor parte de las personas que la utilizan, aunque lo hagan frecuentemente. Tal vez esto sea debido a que "Internet es fácil de usar pero difícil de comprender". ${ }^{1}$ Y como para comprender algo es preciso conocerlo previamente, cabe preguntarse:

\section{¿Qué es Internet?}

Una buena respuesta nos la da Harley Hahn:

"¿Es posible que haya un impulso biológico que nos incite a crear computadoras?. Creo que no. Pero una vez hemos desarrollado estos extraños y maravillosos esclavos, lo más seguro es que haya un programa genético irresistible que nos invita a continuar. En nuestro interior, hay una voz que oímos sólo subconscientemente y sólo como una especie; una voz que nos ordena tomar estas computadoras, conectarlas mediante redes y (...) comunicarnos.

Esto nos lleva a la segunda idea: cuando conectamos computadoras, indudablemente estamos creando algo que es mucho más importante que la suma de sus partes. Como hemos dicho, Internet se compone de millones de personas, pero las computadoras no son importantes; las utilizamos solamente para ejecutar nuestros programas (esto es, para que sigan nuestras instrucciones).

* Doctor en Sociología e Ingeniero de Telecomunicaciones. Titular de la Cátedra de Arquitectura y Tecnología de Computadores, Director del Dpto. de Electrónica y Comunicaciones de la Facultad /Escuela de Informática de la Universidad Pontificia de Salamanca en Madrid. Este artículo fue ponencia en el VII Congreso Nacional de Sociología celebrado en Salamanca los días 20,21 y 22 de septiembre de 2001. 
Lo más importante es algo que aún no podemos entender, la respuesta a la pregunta: ¿Qué sucede cuando millones de personas se reúnen en un lugar seguro, para hablar y compartir?. Esto es Internet." ${ }^{2}$

La tecnología nos da una definición de Internet mas prosaica: una red de comunicaciones, o mejor dicho, una red de telecomunicación de gran cobertura que, igual que la red telefónica, millones de personas de todo el mundo la utilizan diariamente para comunicarse entre sí. Está formada por un amplio conjunto de nodos $^{3}$ interconectados a través de enlaces dedicados, con una topología irregular, que crece conforme se detectan nuevas necesidades y se van sumando nuevos recursos a esta red.

La titularidad de los recursos que componen Internet es de los propios usuarios de la red: cada institución, empresa o proveedor de acceso que se suma a la red, pone sus recursos a disposición de la comunidad Internet, al mismo tiempo que tiene derecho de uso de los que ya forman parte de la misma. De esta forma, Internet crece a medida que se incrementa el número de redes conectadas y de usuarios. También las administraciones fomentan el crecimiento y uso de Internet, facilitando en muchos casos nodos de conmutación y enlaces a la red a distintos colectivos (universidades, centros de investigación, etc) de forma gratuita o subvencionada.

\section{¿Cómo funciona?}

Para que un ET (Equipo Terminal) de usuario ${ }^{4}$ tenga acceso a Internet es necesario que establezca una conexión con un nodo de la red, mediante una línea dedicada específicamente a ese fin $^{5}$ o mediante redes conmutadas que establecen las conexiones de forma temporal (como la red telefónica, que es puente para la entrada en Internet). Al contar con dicha conexión, cada ET queda identificado mediante una dirección única, que lo hará "visible" a cualquier otro ET de la red.

Para el intercambio de información entre ETs se utiliza el protocolo IP (Internet Protocol). Los datos se agrupan en bloques que poseen una estructura normalizada, son los datagramas IP. En estos datagramas se codifica, entre otros parámetros, la dirección del ET destinatario del mismo. A continuación será necesario que el datagrama se desplace por la red en esa dirección. Para ello se envían a través de la línea ya establecida hasta el nodo de acceso que proporciona la entrada en la red. En éste y en los restantes nodos de la red, cada vez que se recibe un datagrama se analiza la dirección que transporta del ET destino, y se determina la mejor ruta para llegar a él. Esto se conoce como función de encaminamiento. A continuación se reenvía el datagrama por dicha ruta. De este modo, salto a salto, la información progresará por la red hasta alcanzar el ET destinatario.

Cada datagrama es tratado por la red de forma autónoma, ya que todos llevan la dirección destino en su cabecera. Debido a ello, los datagramas de una 
misma comunicación pueden desplazarse incluso por distintas rutas, ya que en la función de encaminamiento que aplican los nodos se tiene en cuenta el estado de la red (congestión, averias, etc.) y éste puede cambiar. De hecho, en este tratamiento independiente de cada datagrama es donde reside la robustez del protocolo, al garantizar que un datagrama alcanzará el destino siempre que exista una ruta entre ambos extremos.

Estas características han hecho que Internet sea desde su nacimiento, y aún lo es, la red mundial más rápida e interoperativa, gracias además, y entre otras razones, a su carácter abierto y democrático, en algunos casos casi libertario. Y a que tecnológicamente IP ha sido un éxito como protocolo integrador de las comunicaciones entre los distintos sistemas y ordenadores de la red. De ahí su apelativo: Red de Redes.

\section{¿Cuál es su tamaño real?}

Vinton G. Cerf, considerado el padre de Internet, ha afirmado reiteradas veces que "el numero de usuarios de Internet ha sido siempre difícil de calcular porque no hay un registro central ni un mecanismo estadístico común...". Pero a pesar de ello, existen algunos datos, de estudios serios, realizados al respecto. Uno de los primeros data de 1993, en un articulo publicado por Scientific American y firmado por el entonces Senador, posteriormente Vicepresidente de los Estados Unidos y recientemente candidato a al Casa Blanca, Al Gore, en el que se calculaba que Internet podía estar formada por más de 8.000 redes con una estimación de crecimiento de usuarios de un $10 \%$ mensual. $^{6}$

“...varios estudios llevados a cabo a mediados de 1995 indican que había entre 19 y 23 millones en todo el mundo. Sólo en los Estados Unidos se estimaba que había 8.400.000 usuarios adultos y 1.100.000 de usuarios estudiantes. Dado que otros parámetros de Internet se han duplicado cada año desde 1989 se puede pensar que a mediados de 1996 podría haber en todo el mundo unos 35 millones de usuarios.

(...)

Un estudio realizado por Mark Lottor en Enero de este año (1996) estimaba que había cerca de 94.000 redes en Internet, frente a las 48.000 de un año antes. Casi la mitad de Internet está ya fuera de los Estados Unidos.

(...)

Aproximadamente 134 países de los 230 existentes tienen alguna forma de acceso a Internet aunque la penetración de la red varía de forma espectacular de un país a otro. 


\section{(...)}

Si nos referimos al número de redes, éste empezó a duplicarse cada año a partir de 1988, ha continuado haciéndolo desde entonces y se espera que siga el mismo ritmo al menos hasta el año 2000. Hay que subrayar que el ritmo de crecimiento es tan rápido, o más, fuera de los EE. UU. que dentro de este país y que una simple proyección para los próximos años nos indica que habrá un total de 1.600.000 redes en el año 2000."

En la actualidad, según la NUA Internet Surveys, el número de usuarios conectados a Internet a finales de 2000 era aproximadamente de 400 millones, con un ritmo de crecimiento cercano al $80 \%{ }^{8}$

\section{La "web" y los futuros servicios}

En los últimos años, una de las principales tendencias que viene observándose en el mercado de las telecomunicaciones, es el incremento exponencial del tráfico procedente de la transmisión de datos, que en algunos países ya ha superado al tráfico de voz. Responsable directo de este crecimiento es Internet, cuyo uso se duplica cada seis meses, con más de 11.000 millones de mensajes de correo electrónico (e-mail) diarios. ${ }^{9}$ Su gran aceptación hace que se le considere como uno de los servicios estrella de Internet, entre otras razones por lo cómodo, rápido, económico y fácil que es su uso.

Sin embargo el servicio mas conocido y utilizado en Internet es la World Wide $\mathrm{Web}^{10}$ (WWW), conocida coloquialmente como "web", que facilita la forma de acceder a cualquier tipo de información presente en la red (texto, imágenes, sonido e incluso vídeo). Es decir le otorga a Internet el carácter multimedia. Esto implicó que Internet abandonase el reducto académico y universitario en el que se encontraba, y se convirtiese en un nuevo medio de masas, ofreciendo no solo nuevos accesos a la información y comunicación, sino también nuevas posibilidades para la automatización y control remoto, y, lo que no es menos importante, del comercio y del negocio.

Estos servicios son tan populares, que a menudo se les confunde con la totalidad de las prestaciones que puede ofrecer Internet, pero son sólo una parte de ellas, aunque sea una parte muy importante. ${ }^{11}$

Y en la actualidad, otra cuestión sumamente importante: la inminente integración de las transmisiones de voz, la tradicional telefonía básica, en Internet. Sin olvidar, la incipiente y cada vez convergente difusión audiovisual con las telecomunicaciones, y ambas por Internet. Algo que está dando lugar a un servicio nuevo conocido como "webcasting" o "netcasting", ${ }^{12}$ que consiste en la difusión de contenidos digitales, multimedia e interactivos, a través de Internet. 
Toda esta oferta de servicios hacen crecer, a pasos agigantados, a Internet, originándole unos incrementos exponenciales en número de redes, computadoras y usuarios adheridos a ella. Tales aspectos se han visto favorecidos, en la última década, por los procesos de evolución tecnológica y de liberalización en el campo de las telecomunicaciones, ya que, a una mejora sustancial en la calidad de servicios ya existentes, le suceden otra serie de servicios totalmente nuevos, destinados a ser los protagonistas del cambio social en el nuevo milenio. Son los denominados Servicios Avanzados de Telecomunicación (SAT). ${ }^{13}$

Estos SAT tienen como fin el intercambio de información entre una serie de usuarios normalmente situados en posiciones geográficas diferentes, pudiendo ser éstas fijas o variables. La comunicación entre estos usuarios ha de ser lo más completa posible; por eso la barrera de separación física ha de resultar transparente (imperceptible) para ellos. Es decir, se ha de parecer lo más posible a la presencia real de los usuarios en la comunicación. Así, si el simple intercambio de información sonora o escrita no basta, sino que también es necesaria la visual, la comunicación ha de ser multimedia. Se permite el intercambio de voz, textos, vídeo, gráficos, etc., de acuerdo a los requerimientos de cada caso.

Para poder hacer uso de un SAT el usuario necesita un terminal o equipo que se conecte a una red de telecomunicación. Esto significa que el usuario deberá ubicarse allí donde se encuentre el terminal y éste a su vez deberá estar situado donde exista posibilidad de conexión a la red utilizada, lo que limita la movilidad del usuario. Con objeto de que esto no ocurra hay que dotar al usuario de los SAT de movilidad. Así el usuario puede continuar haciendo uso de los SAT independientemente de su continuo desplazamiento de un lugar a otro.

Para calibrar la importancia adquirida por los nuevos servicios de telecomunicación, basta con tener en cuenta que desde los años sesenta el sector servicios, en su globalidad, aportaba ya más de la mitad del PIB en los países industrializados y con economía de mercado, y que este sector ha seguido creciendo por encima del resto, en términos de PIB y empleo, con un crecimiento desigual dentro de él. Pues bien, los servicios beneficiados han sido aquellos que están relacionados de alguna manera con las telecomunicaciones (financieros, turismo, etc.), y los servicios de telecomunicaciones propiamente dichos.

$\mathrm{Si}$ a todo lo anterior añadimos que la mayoría de los servicios tradicionales, a excepción del turismo y del transporte, que se producían y consumían localmente ya han dejado de hacerlo, ya que en la actualidad las empresas productoras de bienes de consumo se articulan alrededor de los servicios de telecomunicación:

“...el efecto combinado de la conversión digital y el enorme incremento de la capacidad de transporte de las modernas telecomunicaciones, colocan a los servicios, como mínimo, a la altura de las mercancías en el intercambio económico." ${ }^{14}$ 
Todos estos datos e incontestables cifras sobre la aceptación de Internet y sus previsiones de futuro, son las que, a pesar de lo abstracto de su concepto, la llevan a ser catalogada como un avance de la humanidad, comparable a cualquiera de los grandes hitos que han marcado la vida del ser humano.

\section{TECNOLOGÍAS E INFRAESTRUCTURAS}

Para llegar a la situación anteriormente descrita han sido necesarios no pocos avances en los campos de la computación y telecomunicaciones, y en esta última, también en su vertiente política, al transformar los seculares monopolios en un sistema regulado pero de libre competencia, que ha propiciado el desarrollo de las redes de telecomunicaciones y sus tecnologías asociadas.

\section{Génesis}

Hasta la década de los sesenta, las únicas redes de telecomunicación existentes, además de las de radiodifusión, eran las telegráficas y las de telefonía. Los operadores tradicionales (PTTs) ${ }^{15}$ de los distintos países habían desarrollado e implantado redes nacionales adecuadas para ello, capaces de conexionarse entre sí para la transmisión de señales telegráficas y voz.

Con la aparición de los ordenadores, surge la necesidad de conectar unos con otros, existiendo como única infraestructura, las citadas redes de telefonía. Este tipo de redes basa su funcionamiento en la conmutación de circuitos, cuya característica principal es que ofrece una determinada capacidad de transmisión, asignada en exclusiva y durante todo el tiempo que dure la comunicación, ${ }^{16}$ aunque en determinados intervalos de tiempo no se transmita información, como ocurre con los silencios de una conversación telefónica. Característica que se mantiene incluso si son datos los que se transmiten por ella.

Existe un retardo mínimo y constante (el de propagación por el circuito) para el tránsito de la información, si bien es necesario un tiempo de establecimiento del circuito. La tarificación se hace por distancia entre usuarios y tiempo de conexión, independientemente de que se transfiera o no información. Una vez establecido el circuito, la red es transparente a la información, ya que no realiza ninguna función de cambio de velocidad o código en los datos, ni tratamiento alguno sobre ellos.

El desarrollo de la informática, y la conjunción de ésta con las telecomunicaciones da lugar a una nueva tecnología, conocida como Telemática ${ }^{17}$ o Teleinformática, para la que ya son insuficientes y en algunos caso ni siquiera son válidas las redes de telecomunicaciones existentes, que estaban diseñadas para transmitir exclusivamente señales de carácter analógico. ${ }^{18}$ Esto provocó la necesidad de diseñar y desarrollar redes específicas para transmitir datos provenientes de ordenadores, que son señales digitales. 
La tecnología escogida para la implementación de este tipo de redes fue la "conmutación de paquetes", en un intento de compartir los limitados recursos de red y los tiempos de latencia (retardo). Para ello, la información de usuario se agrupa en unidades de longitud limitada ("paquetes"), ${ }^{19}$ que se transportan entre los nodos, desde el origen al destino mediante procesamiento y retransmisión; cuando un nodo recibe un paquete, analiza su cabecera (procesamiento), y lo reenvía por un enlace de salida hacia el siguiente nodo (retransmisión).

Aunque éste tipo de tecnología consume toda la capacidad de enlace disponible, optimiza el uso de dicha capacidad, ya que en cada conexión sólo se utiliza capacidad de la red cuando se llevan a cabo intercambios, pudiendo así compartirse la capacidad disponible en los enlaces, entre múltiples usuarios. Este tipo de redes están diseñadas para soportar aplicaciones interactivas, con necesidades puntuales de intercambio, e intervalos de inactividad entre ellas (modo ráfaga), ${ }^{20}$ en cuyas aplicaciones deben garantizarse tiempos de retardo reducidos y limitados (decenas de milisegundos).

La implementación de esta tecnología dio lugar a un concepto nuevo, de una importancia futura insospechable en 1978, fecha de publicación del Informe Nora-Minc, a pesar de que en dicho informe ya se preconizaba:

"La 'telemática', a diferencia de la electricidad, no transmite una corriente inerte, sino información, es decir, poder. (...) La telemática no constituirá una red más, sino una red de otra naturaleza, que hará interactuar imágenes, sonidos y memorias, y transformará nuestro modelo cultural." ${ }^{21}$

La consecuencia inmediata del desarrollo telemático fué el nacimiento de las redes de datos, con tecnología de conmutación de paquetes, que crearon las diferentes administraciones en sus respectivos países. Pero los ETs utilizados para esta tecnología eran costosos y su uso quedaba reducido a grandes compañías, y por ende poco accesibles al gran sector residencial de usuarios, que, como consecuencia del descenso del coste de los ordenadores personales demandaban la posibilidad de conectarlos entre sí, a larga distancia. Por esta razón se desarrolló una tecnología con la que se podían conectar ordenadores, incluso por la red telefónica convencional, a través de un modem, que posibilitaba la transmisión de datos procedentes de los ordenadores, a través de las redes analógicas de telefonía.

Las redes de datos lógicamente se ubicaron desde un primer momento dentro de las tradicionalmente denominadas telecomunicaciones, de las que aún se consideraban excluidas las redes de difusión audiovisuales, no solamente por la diferencia de los soportes que utilizaban, ${ }^{22}$ sino además por principios básicos de funcionamiento y de explotación de los soportes: punto a punto y "duplex" (bidireccional simultaneo) en las redes de datos, y "simplex" (unidireccional) y punto a multipunto en las de radio y TV. 


\section{Convergencia Digital}

La digitalización previa a la transmisión de señales analógicas, como la voz y el vídeo, hace que estas señales no se diferencien a la hora de ser transmitidas de las señales de datos generados por un ordenador. Por esto, las redes telemáticas no han quedado reducidas a redes de transporte de datos informáticos, sino de cualquier tipo de información. Además, en estas redes se ha llegado a tal grado de integración entre computación y telecomunicaciones, que además de ser difícil detectar la frontera de separación entre ambas, las capacidades de procesamiento de información pasan a ser parte del sistema de telecomunicación.

Es precisamente la digitalización, la innovación tecnológica que más ha transformado los sistemas de telecomunicación en las dos últimas décadas. Aunque la transmisión digital suele requerir mucho más ancho de banda que su señal analógica equivalente, ${ }^{23}$ sin embargo sus ventajas compensan con creces esa mayor ocupación del canal de transmisión.

Si el proceso de digitalización ha afectado de una forma transcendental a los procesos industriales, los sistemas de telecomunicación no han ido a la zaga, ya que se han visto transformados todos sus componentes: los ETs utilizados para conectarse a las diferentes redes, cada vez más potentes y con más responsabilidad en la comunicación; la conmutación (llevada a cabo en los nodos de la red) con la introducción de ordenadores e informática en ella; la transmisión, favorecida por la incorporación de nuevos medios o soportes (microondas y fibra óptica), y de técnicas de compresión y multiplexación. ${ }^{24}$

Como consecuencia de este proceso, en la actualidad, a excepción del acceso telefónico vocal y de la señal de TV, que, salvo en casos muy aislados, siguen transmitiéndose de forma analógica, el resto de los sistemas de telecomunicación utilizan técnicas digitales. Eso no quiere decir que existan impedimentos técnicos para que las señales anteriormente comentadas no se puedan transmitir de forma digital, sino que tradicionalmente se han estado transmitiendo así, tanto por su naturaleza analógica, como porque los sistemas estaban diseñados para ello. No obstante, con la progresiva digitalización de los sistemas de telecomunicación, estos servicios se comienzan a prestar con técnicas digitales: telefonía vocal por RDSI (Red Digital de Servicios Integrados), y televisión digital por satélite e infraestructuras terrenas.

Con la incorporación de la tecnología digital, tanto en los sistemas de transmisión como en las centrales de conmutación, y la evolución de los soportes de transmisión, se ha producido una importante transformación de las redes de telecomunicación, fundamentalmente en tres aspectos:

Primero.- Un incremento importante en la capacidad y la calidad de transmisión. Gracias a la digitalización de señales de naturaleza analógica, tales 
como la voz, texto e imágenes, se consigue una mayor eficacia de tratamiento de este tipo de información, unido a la propia naturaleza digital de las señales de datos procedentes de los Ets.

Segundo.- Un aumento de la velocidad y capacidad de conmutación, y la incorporación de la inteligencia a la red, como consecuencia de la fabricación de centrales de conmutación o nodos de red, con tecnología VLSI, en las que el tratamiento y procesado de las señales se realiza de forma digital.

Tercero.- Un aumento considerable del numero de canales sobre un solo soporte físico; producto de la evolución de éstos hacia sistemas de fibra óptica y a los sistemas de transmisión de la información, tales como el MIC (Modulación por Impulsos Codificados).

\section{Sistemas y redes de transmisión}

Para que todas estas transformaciones pasaran de la potencia al acto, era necesario que la Banda Ancha se hiciera realidad. Y se ha hecho, gracias a un nuevo concepto que afecta por completo a todo el sistema de telecomunicación, el Modo de Transferencia Asíncrono (ATM).

Hasta la llegada del ATM, la evolución de las redes de telecomunicaciones, se iba produciendo de una forma escalonada y paulatina: primero se digitalizaron los enlaces entre centrales, después los centros de conmutación, y, por último, el bucle de abonado.

Los ETs utilizados en las redes analógicas, tambien, han podido adaptarse para su conexión con la RDSI-BE (Banda Estrecha) mediante interfaces adaptadores. En suma, una evolución tecnológica "no traumática". Pero el ATM ha supuesto la ruptura con postulados anteriores, al incorporar una filosofía de funcionamiento totalmente nueva: su puesta en práctica y posterior desarrollo necesitan que el sistema de transmisión, la tecnología de conmutación y la infraestructura sean de nueva generación. Esta última ha de basarse en soportes de gran capacidad de transmisión y, sobre todo, de gran fiabilidad.

En concreto la transmisión. Para posibilitar las altas velocidades propuestas por ATM, ha sido necesario desarrollar sistemas de transmisión síncronos como el SONET (Synchronous Optical Network), propuesto por ANSI (American National Estándar Institute), en 1987, y convertido en el estándar americano de fribra óptica, con una velocidad de transmisión de 51,840 Mbps. Por su parte, la UIT-T (Unión Internacional de Telecomunicaciones) culminó, en 1989, una serie de recomendaciones que definían la Jerarquía Digital Síncrona JDS, con una velocidad básica de 155,520 Mbps, que, como puede observarse, corresponde exactamente a tres veces la velocidad básica SONET. Por lo que, aunque SONET y JDS son dos estándares diferentes, permiten su interfuncionamiento en sistemas de jerarquías superiores a los 155,520 Mbps. 
Respecto a la conmutación. ATM busca optimizar las ventajas de los sistemas ya existentes, circuitos y paquetes, estableciendo la necesidad de construir un modo de conmutación nuevo, que combine las ventajas de ambos. Así se implementa la conmutación rápida de circuitos FPS (Fast Packet Switching), en donde los recursos disponibles son utilizados únicamente cuando la información es enviada, quedando liberados si no se envía información.

Por último, la infraestructura necesaria para los requisitos de ATM, la ofrece RDSI-BA (Banda Ancha) sobre cable de fibra óptica, surgida de la necesidad de integracion de servicios que existe en RDSI-BE, pero creando soluciones tecnologicas totalmente diferentes e incompatibles con las anteriores, dada la necesidad de un ancho de banda más grande y con velocidades de transferencia superiores a 2 Mbps.

No obstante, la RDSI-BA, durante su proceso de implantación, está coexistiendo con las redes existentes, convirtiéndose en autopista común para transmitir señales de voz, vídeo y datos, y los servicios de ellas derivados, tanto actuales como futuros. Esta característica es conocida como "escalabilidad" y "flexibilidad" de la red.

En esta nueva red, ya no son válidos los clásicos ETs analógicos, pero es que, incluso los novedosos ETs digitales de la RDSI-BE, que aún se encuentran en fase de incorporación al mercado, tampoco son válidos.

Se da una cierta unanimidad sobre esto, al afirmar que en el futuro, el teléfono, el fax, el PC, la TV, etc., estarán integrados en un único ET, que será algo más que una maquina multimedia, al reunir todos los servicios imaginables de audio, vídeo, gráficos y texto, y ofrecer un alto nivel de estandarización. ${ }^{25}$

\section{Los satélites}

Ahora bien, si en algún sistema de telecomunicación se está produciendo un auténtico cambio conceptual, es en el de satélite, que con sólo 50 años de edad, aproximadamente, se va a hacer interactivo. Para ello, ha sido necesario incorporarles, además de las tecnologías anteriormente descritas, algunas innovaciones tecnológicas. Una de ellas es la concentración del haz, para hacer posible, entre otras razones, la reutilización de frecuencias, con el consiguiente mejor aprovechamiento del espectro.

Otra innovación se produce al intentar resolver uno de los problemas más importantes de los satélites geoestacionarios GEO (Geostationary Earth Orbit), y, hasta ese momento, también de las comunicaciones vía satélite: la latencia, que debe ser casi imperceptible, sobre todo para las aplicaciones interactivas.

Eso se consigue básicamente acercando los satélites a la tierra para reducir distancias y, reducir así la latencia, ${ }^{26}$ es decir, situando a los satélites en una órbita mas baja, dando lugar así a los LEO (Low Earth Orbit), ${ }^{27}$ situados entre 200 y $2.000 \mathrm{Km}$. 
En esta órbita al variar el satélite su posición relativa respecto a la tierra, le hace no estar permanentemente visible desde un punto. Por esto se requiere una flota de satélites sobre cada una de las órbitas, para poder tener acceso permanente desde un punto fijo y conseguir una cobertura mundial. Es lo que se viene a denominar "constelaciones de satélites".

La elección entre uno u otro sistema presenta ventajas e inconvenientes, ${ }^{28}$ y depende del fin que se les asigne. Los LEO son adecuados para aplicaciones interactivas, como son las conexiones de redes de alta velocidad, las teleconferencias y la telemedicina, mientras que los GEO son mas adecuados para comunicaciones de datos o para la distribución de vídeo.

Las constelaciones de satélites, además de haber acabado con el problema de los retardos (latencia), han abierto la posibilidad de que el sector espacial se pueda introducir en las comunicaciones móviles celulares y que los sistemas de posicionamiento como el GPS (Global Positioning System), se integren en los sistemas de comunicaciones, como un elemento más, para reforzar la eficacia, prestaciones y campo de aplicación de las comunicaciones vía satélite.

Pero no son estas las únicas aportaciones de los LEO. También permiten establecer redes de las mismas características que las terrestres, incluyendo las de fibra óptica, en lo que se refiere al ancho de banda y la velocidad de transmisión. Hasta tal punto que este tipo de redes satelitales se denominan "fibra óptica en el cielo", siendo una alternativa muy competitiva respecto al cable, ya que los precios, además de no variar con las distancias geográficas, eliminan la dificultad del cableado en áreas no urbanas.

La posibilidad de transmitir masivamente información a través de estas redes, sin importar fronteras geográficas y políticas, trae como consecuencia la posibilidad de un acceso inmediato a la información. Esto les confiere una inusitada relevancia y las hace imprescindibles en la actualidad para cualquier actividad económica, social y cultural.

Nace así el comercio internacional de la información, con un impacto definitivo para el desarrollo del sector terciario (financiero, turístico, etc.). En suma, es la globalización de estos servicios, que alcanzan su zenit con la implementación de Internet.

\section{EVOLUCIÓN DE INTERNET}

Década de los 60, plena guerra fría. En la OTAN existe un gran temor a un ataque nuclear por parte de la U.R.S.S. En realidad este miedo era igual en ambos bloques, pero Estados Unidos se planteó una serie de medidas entre las que se incluyó proteger lo que evidentemente sería objetivo prioritario en un potencial ataque de ese tipo: las comunicaciones.

El equilibrio de poder que garantizaba el respeto mutuo, se basaba en la capacidad de retaliación, es decir, si una de las grandes potencias iniciaba el conflicto 
lanzando sus misiles nucleares a la otra, siempre quedaría un poder de respuesta en esta última que provocaría también daños en la primera, muy difíciles de estimar a priori. Pero si ese ataque inicial lograba destruir las comunicaciones, el caos y la confusión impedirían organizar un contraataque efectivo. El "quid" de la cuestión era, ¿cómo mantener las comunicaciones después de un ataque nuclear?.

\section{Sus orígenes}

Ante tal situación, la Agencia de Proyectos de Investigación Avanzada de la Defensa, conocida como DARPA (Defense Advanced Research Projects Agency), ${ }^{29}$ intenta crear una red capaz de interconectar ordenadores de forma fiable y que siguiese funcionando incluso cuando se destruyeran partes importantes de la misma.

Para ello se necesitaba una robusta y segura red de mando y control, que uniera las diferentes bases militares distribuidas por toda su geografía, y que en el caso de ser interceptada, impidiera que se pudiera conocer, interrumpir, e incluso cambiar, el contenido de los mensajes. Algo que las tradicionales redes telefónicas no eran capaces de ofrecer. El tradicional sistema telefónico implicaba el uso de centrales, unas más importantes que otras, y sin duda uno de los misiles enemigos iría destinado a algún nodo central neurálgico, por lo que había que hallar una solución al posible problema, con una filosofía totalmente diferente.

Tres eran los principios básicos mínimos, que debería cumplir el nuevo sistema de comunicaciones:

Primero.- La red no debía ser jerárquica, y todos los nodos de comunicaciones habrían de tener la misma importancia en valor estratégico, de tal forma que sólo sería destruida eliminando todos sus nodos y evitando así la posibilidad de colapso mediante un ataque selectivo.

Segundo.- Los mensajes nunca se deberían transmitir enteros, sino que se dividirían en fragmentos ("paquetes") identificados con información de control, de forma que si se interceptaban algunos de estos paquetes el mensaje original fuese ilegible, y sin embargo se pudiese reconstruir en destino, cuando se recibiesen todos los paquetes.

Tercero.- Los fragmentos del mensaje deberán ir a su destino, por rutas diferentes en la mayoría de los casos. Además, ni el origen ni el destino tienen porqué saber qué ruta seguirán cada uno de los paquetes, sino que eso es algo que se debe decidir sobre la marcha, mientras se va transmitiendo la información.

Estas especificaciones cristalizaron en 1969, en una red de comunicaciones que se denominó ARPANET (ARPA NETwork)..$^{30}$ Debido a su concepción y financiación, el acceso a ARPANET en los primeros años se limitó a usos militares (contratistas de defensa y universidades que realizaban investigación en este campo en colaboración con el Departamento de Defensa). Pero pronto pasó a ser controlada por los expertos de las universidades que tenían más conocimientos en 
comunicaciones que los mandos militares, y que contaban con bases de información amplísimas en sus bibliotecas ya informatizadas.

Cuatro nodos de conmutación, situados en el Instituto de Investigación de Stanford y en las universidades de los Angeles, Sta. Bárbara y de Utah, ${ }^{31}$ constituyeron el germen de ARPANET. Con el paso del tiempo se le fueron añadiendo otros nodos, que no eran más que nuevas computadoras conectadas a ellos. Éstas, además de sus funciones de cálculo y uso tradicional, encaminaban los mensajes, es decir, los recibían y comprobaban a quién iban dirigidos, si era para ellos los aceptaban y, si no, lo transmitían a otro nodo que pudiera acercar más el mensaje al destino. Por tanto, almacenaban y retransmitían los paquetes de los diferentes mensajes a los ETs destinatarios de la información.

En 1972, se lleva a cabo la International Computer Communication Conference en la que Bob Kahn realiza una demostración de ARPANET, con Vinton Cerf como jefe del proyecto. Un año más tarde, en 1973, se produce la primera conexión internacional con ARPANET, entre el University College of London (Inglaterra) y el Royal Radar Establishment (Noruega), y en septiembre de ese mismo año, Cerf y Kahn presentan, en el Reino Unido, concretamente en la Universidad de Sussex (Brighton), las ideas básicas de Internet.

Para poder unir todas las redes entre sí, era necesario un protocolo de comunicaciones común a todas ellas. Alentado por centros universitarios, bajo la premisa implícita en el significado de Universidad: estar abierta a todo el que desee acceder a ella, es decir, su universalidad. Y en 1974 empieza a darse forma a la arquitectura y protocolos de la red. Es entonces, cuando Kahn y Cerf publican "A Protocol for Packet Network Intercommunication", donde se especifican con detalle el diseño de un programa para el control de la transmisión, que se dio a conocer como TCP (Transmision Control Program). En 1979 se creó un comité para coordinar el diseño de un protocolo de transporte y otro de red, capaces de interconectar ordenadores de distintas redes, cristalizando en 1982 cuando el protocolo TCP e IP (Internet Protocol), son adoptados oficialmente por ARPANET como protocolos TCP/IP.

Una vez resueltos los problemas de interconexión, a principios de los ochenta, empezaron a conectarse progresivamente a la red inicial, otras redes del entorno científico de Estados Unidos, como forma de intercambio rápido de opiniones, consultas, trabajos, etc., con lo cual la comunidad de usuarios fue aumentando rápidamente.

En 1983 ARPANET se dividió en dos redes distintas: MILNET para usos militares, y ARPANET para usos científicos. Ese mismo año, el protocolo TCP/IP fue integrado en el sistema operativo Unix de Berkeley (UCLA), lo que contribuyó poderosamente a su difusión por las demás Universidades como protocolo de comunicaciones, construyéndose sobre él una serie de utilidades para servicios de red. Simultáneamente, numerosos fabricantes comenzaron a lanzar al mercado 
equipos basados en TCP/IP, lo que contribuiría notablemente a su éxito. Sin olvidar otro factor no menos importante en su expansión: el apoyo dado por la Fundación Nacional de Ciencias (NSF), que inició en 1985 la interconexión de sus seis centros de supercomputación con este protocolo.

\section{Organismos de Internet}

La primeras iniciativas al respecto datan de 1972 con la creación de Internetworking Working Group (INWG) y de 1979, con USENET (USErs NETwork) y un comité para la coordinación del diseño de TCP/IP, respectivamente. Pero fue en 1986, cuando la NSF fundó NSFNET (National Scientific Foundation NETwork), con el propósito de unir a todos los investigadores de los diferentes estados de USA con macrocentros de cómputo. Algo que facilitó a toda la comunidad científica americana el acceso e interconexión con sus ordenadores, y estructuró el nacimiento de la Red.

La NSFNET se expandió rápidamente para conectar las redes académicas de las universidades y demás centros de investigación, y empezó a reemplazar a ARPANET, democratizándose finalmente, una vez abierta al tráfico comercial y después de modernizar las líneas telefónicas que unían todos sus nodos. ARPANET, después de cumplida su importante misión, se había convertido, ${ }^{32}$ vía NSFNET en Internet, dejando de estar limitada geográficamente a USA. A partir de ese momento, las infraestructuras militares de la red quedarán aisladas constituyendo su propia red denominada MilNet (Militar Network).

El NSFNET fomentó la utilización de TCP/IP en redes regionales, centros de investigación, privados y gubernamentales, provocando un crecimiento espectacular de la red. A los siete años de su concepción la red conectaba aproximadamente a 20.000 ordenadores, pasando a multiplicar la capacidad de sus líneas troncales por cien, convirtiéndola en la espina dorsal de Internet.

Lo más llamativo es que la red en sí, desde sus orígenes, ha carecido de una empresa privada o entidad pública que las gestione, aunque en 1979 ARPA creó una junta para el control y configuración de Internet, la ICCB (Internet Configuration Control Board), ${ }^{33}$ que posteriormente, en 1983, pasó a llamarse Junta de Actividades Internet, denominada IAB (Internet Activities Board), ${ }^{34}$ que coordina la investigación y evolución de los protocolos utilizados en la misma. Es precisamente en estas fechas cuando se incorpora el sistema de nomenclatura de dominios DNS (Domain Name System) ${ }^{35}$ para facilitar el direccionamiento, ya que permite a los usuarios utilizar nombres, en lugar de las incómodas direcciones numéricas de IP.

En 1986 se reorganizó la Junta de Actividades de Internet, creándose dos grupos, en los que empezaron a participar gran cantidad de voluntarios:

$1^{\circ}$ ) IRTF (Internet Research Task Force): que coordina las actividades de 
investigación relacionadas con los protocolos TCP/IP y la arquitectura de Internet en general.

$2^{\circ}$ ) IETF (Internet Engineering Task Force): que se encarga de los problemas de ingeniería a corto y medio plazo, dividida a su vez en áreas para tratar temas específicos y resolución de problemas. ${ }^{36}$

Para mantener y facilitar la documentación existente, sobre TCP/IP y la red, se creó el Centro de Información de Internet INTERNIC (Internet Network Information Center), que a su vez coordina las propuestas de nuevos protocolos o revisiones a los existentes mediante unos informes técnicos llamados Solicitudes de Comentarios de Internet RFC (Request for Comments).

Cuenta además, desde 1992, con la Sociedad de Internet ISOC (Internet SOCiety), dedicada a promover Internet en todos los sus aspectos. Aglutinando a mas de 175 organizaciones y 8.600 miembros de 170 países. $^{37}$

Finalmente, ante la importancia de asignación de direcciones y nombres en Internet, estas competencias se encuentran gestionadas por el IANA (Internet Assigned Numbers Authority), máxima autoridad en la asignación de direcciones IP y de dominios (DNS) para Internet, aunque delegue en los denominados registros nacionales. ${ }^{38}$

\section{La Segunda generación de Internet}

En 1989 se produce una innovación en Internet, la creación de la página "web", que ha sido la causante de la gran explosión de Internet, y el gran impulsor de la segunda generación de Internet, porque entonces empieza a vislumbrarse que los recursos de los que dispone Internet, son claramente insuficientes e inadecuados para soportar el incremento de la demanda.

La insuficiencia se concreta en el rendimiento ofrecido respecto al ancho de banda y velocidad de transmisión reales, ya que, aunque en las redes troncales (backbones), sus valores nominales estén situados en el rango OC-12, es decir 622 Mbps, en la práctica no se alcanzan velocidades superiores a las decenas de Kbps. Y la inadecuación se debe a que el protocolo utilizado actualmente por Internet, el Ipv4, no es capaz de ofrecer prestaciones tales como: garantizar atributos de calidad de servicio QoS (Quality of Service), ni garantizar una latencia máxima de red, además de no proporcionar una seguridad adecuada ni poder reservar ancho de banda.

Aunque es cierto que se han ido creando "añadidos" para que Ipv4 "parcheara" estos inconvenientes. El problema reside en que, por separado, cualquiera de las aplicaciones anteriores resulta relativamente sencillo implementarlas, teniendo dificultad en utilizar dos a la vez, y siendo casi imposible el uso simultaneo de tres o más.

Pero aún había algo más importante y de mucha gravedad. En 1993 saltan las alarmas. La comunidad Internet se enfrenta con el mayor problema que hasta 
entonces había tenido la "Red de Redes": no puede soportar el ritmo de su propio crecimiento. No se trataba solamente de un problema de ancho de banda y de velocidad, que se podia solucionar aumentando la capacidad de los enlaces. Tampoco de un problema de calidad de servicio ni de otro tipo de prestaciones avanzadas, que se podían paliar con las modificaciones del protocolo anteriormente citadas. La razón del problema está en el propio diseño del mecanismo de direccionamiento IP. Un diseño, que no había previsto la vertiginosa expansión que Internet estaba sufriendo, y que conduciría inexorablemente a la muerte de Internet en menos de dos años.

Desde sus orígenes, las direcciones de Internet proporcionadas por el protocolo IPv4 están formadas por una secuencia de 32 bits, estas direcciones IP están divididas en clases que identifican los distintos tipos de redes en la que se encuentra el usuario y, dentro de ésta, cada ET concreto que en ese momento es direccionable. A pesar del potencial tamaño de direccionamiento proporcionado por IPv4 de más de 4.000 millones de direcciones $\left(2^{32}=4.294 .967 .296\right)$, algunas de las clases en las que se divide se agotan. La estimación que Vinton Cerf realizaba en 1977: "32 bits debería ser un espacio de direcciones suficiente para Internet»" no ha podido resistir el paso del tiempo.

Las razones; la falta de previsión del crecimiento de la red durante la década de los 80, que cristalizó en tres aspectos fundamentalmente: la falta de coordinación en la asignación de direcciones, que se realizó sin ningún tipo de optimización, dejando incluso grandes espacios discontinuos de direcciones, el criterio de división de las direcciones en tres clases, en función del tamaño de las redes físicas, y la política de repartición de direcciones de acuerdo a criterios geográficos, para optimizar el rendimiento de los algoritmos de encaminamiento. ${ }^{39}$

Es cierto que, como una posible solución, pudiera pensarse en la renumeración y reasignación del espacio de direccionamiento del IPv4, sin embargo, esto no es viable, no solo por los esfuerzos de coordinación que a nivel mundial fuesen necesarios, sino que, además, la falta de direcciones no es igual en todos los puntos de la red, que es casi inapreciable dicha escasez en E.E. U.U., pero empieza a agravarse en Europa y es crítica en Japón.

Por tanto, las soluciones que se han ido adoptando, todas ellas coyunturales, hasta la migración a IPv $6^{40}$ como protocolo de la nueva Internet, son: una consiste en eliminar el concepto de clases de direcciones mediante un mecanismo de direccionamiento CIDR (Classless Inter-Domain Routing), uniendo diversas redes en una de orden superior (superneting). Otra solución, es la que adoptaron los proveedores de servicios de Internet, ISPs (Internet Service Providers), que proporcionan a sus clientes direcciones IP privadas mediante mecanismos de traslación de direcciones NAT (Network Address Translation), usando una única dirección IP pública para toda una red privada. 


\section{INTERNEXT (INTERnet NEXT generation)}

Para resolver todas estas deficiencias de nuevo se movilizaron universidades, centros de investigación, empresas y organismos, gubernamentales e internacionales, con el único y exclusivo fin de reinventar Internet, ${ }^{41}$ pero sin una ruptura traumática con la tecnología existente. Es decir, el cambio ha de producirse de manera que durante todo el tiempo que éste dure, no se interrumpa el servicio actual de Internet. En cualquier caso, este proceso supondrá nuevo software y hardware, un aumento de servicios por parte de los operadores y nuevas herramientas de gestión de red, para ejecutar aplicaciones de alto rendimiento. Todo ello con la nueva versión IPv6 como piedra angular.

\section{IPv6}

El protocolo Ipv6 incrementa su capacidad de direccionamiento considerablemente, de 32 a 128 bits, por lo que el espacio de direcciones pasa a ser $2^{128}=340.282 .366 .920 .938 .463 .463 .374 .607 .431 .768 .211 .456$. Para hacerse una idea de lo que esta cifra significa, basta decir que con una asignación ideal, se dispondría de 665.570.793.348.866.943.899.599 direcciones IP por $\mathrm{m}^{2}$ de la superficie terrestre.

Sin embargo la asignación de direcciones dista mucho de ser ideal. Considerando el caso más desfavorable y utilizando la misma eficiencia que en IPv4, el número de direcciones disponible por $\mathrm{m}^{2}$ de la Tierra sería de 1.564, océanos incluidos.

Pero IPv6, además de posibilitar una mayor capacidad de conexión de dispositivos a Internet, ofrece características sumamente novedosas e importantes como: ${ }^{42}$

- "plug and play": autoconfiguración, que posibilitará el uso de Internet de una manera mucho mas sencilla, por parte de los ususarios, que la actual.

- Ipsec: mayor seguridad intrínseca en el núcleo del protocolo, característica fundamental para aumentar la confianza de los usuarios en Internet.

- QoS y CoS (Class of Service): difernetes calidades para un mismo servicio, y diferentes clases de servicio, aplicando tarificaciones diferentes.

- "always on": siempre conectados, como ahora el teléfono, se podrá utilizar Internet sin necesidad del elaborado proceso actual.

"always there": se podrá acceder sin problemas a las aplicaciones y sitios deseados independientemente del estado de la red.

- autenticar usuarios e información en la Web, privacidad de datos, comprobación de firma electrónica, etc.

En EE.UU. se produjeron las primeras iniciativas y proyectos al respecto, ${ }^{43}$ que devinieron en lo que se denominó Internet $2:^{44}$

La primera de ellas por parte de la NFS (National Science Foundation). El 
proyecto denominado vBNS (very high performance Backbone Network Service) se puso en funcionamiento en la primavera de 1995, mediante una red troncal dedicada de alta velocidad MBone (Multicast Backbone) ${ }^{45}$ con servicios de última generación. Comenzó conectando cinco centros de procesado vectorial (supercomputación), y en 2000 conectaba ya, aproximadamente, a 100 organismos de investigación con velocidades de 2,4 Gbps. Además, vBNS utiliza un protocolo independiente para difusión, el PIM (Protocol-Independent Multicast) de alto rendimiento, así como multiplexación por división de ondas (WDM), y está trabajando para incorporar la nueva versión de TCP/IP, el IPv6, capaz de ofrecer servicios de ancho de banda reservado que establezca una ruta especial a través de Internet.

El segundo proyecto comenzó en septiembre de 1997, y está siendo desarrollado por una corporación de Universidades, UCAID (University Corporation for Advanced Internet Development). Tiene como objetivo construir otra red paralela a Internet de uso general y no ser una segunda versión tecnológica de Internet, como erróneamente podía interpretarse por su denominación. Enlaza unas 100 universidades y desarrolla aplicaciones de red de próxima generación que abarcan todas las disciplinas académicas. También permite experimentar métodos para potenciar los GigaPOP (Gigabit Point of Present), puntos en donde se suma a Internet el alto tráfico proveniente de las universidades y los enlaces vía satélite.

La propia Casa Blanca, en 1996, inició una experiencia denominada NGI (Next Generation Internet), que engloba proyectos tecnológicamente heterogéneos, pero con un objetivo común: desarrollar y utilizar dos bancos de pruebas de gama alta con un rendimiento en términos de velocidad, de extremo a extremo, $100 \mathrm{y}$ 1000 veces más rápido que la Internet actual, es decir del orden de $100 \mathrm{Mbps}$ y 1 Gbps. Cinco son los proyectos en marcha, que engloba esta iniciativa:

- NTONC (National Transparent Optica Network Consortium): banco de pruebas para experimentar el rendimiento de componentes avanzados de comunicaciones ópticas.

- MONET (Multiwavelength Optica Networking): para la experimentación de una red óptica nacional con múltiples longitudes de onda.

- ATDNet (Advanced Technology Demostration Network): para el despliegue de tecnologías ATM y SONET, por parte de las Agencias Federales.

- CAIRN (Collaborative Advanced Interagency Research Network): para la experimentación con protocolos IPv6.

- Advanced Communications Technology Satellite ATM Internetwork: este proyecto relacionado con satélites, experimenta con la señalización de red, la gestión de colapsos, la multidifusión IP y ATM y las pasarelas con LAN no ATM.

Otra iniciativa sumamente importante, es la llevada a cabo por la IETF que desarrolla un proyecto IPng (Internet Protocol next generation) ${ }^{46}$ mediante el cual se intenta sustituir, desde 1999, el IPv4 por los IPv6, que servirán de soporte para multidifusión de datos. Estos nuevos protocolos IPng incluyen dos cabeceras 
que aumenten la seguridad en la comunicación, una de autentificación y otra de seguridad de encapsulación. También se busca satisfacer una calidad de servicio (QoS) y garantizar y controlar características como la capacidad, la gestión de paquetes perdidos, la sincronización, la discriminación de paquetes, el control de admisión y la contabilidad y facturación.

\section{Internet $3^{\text {a }}$ generación}

Aunque no sea de forma explícita, todas las soluciones de lo que se denominó Nueva Generación de Internet, apuntan a Ipv6 como nuevo protocolo, y esa es la tendencia que se mantiene actualmente.

Esta necesidad, cada vez mas acuciante, quedó confirmada por los datos ofrecidos en febrero de este mismo año en el "Madrid Global IPv6 Forum": de los 200 millones de direcciones efectivas que constituyen el límite de direccionamiento del IPv4, en la actualidad ya han sido consumidos 109 millones. ${ }^{47}$

Sin embargo, un handicap entorpece la progresiva sustitución de IPv4 y sus modificados por IPv6; el ciclo de implantación de un protocolo de red es lento (de cinco a diez años).

Para acortar al máximo estos plazos, ha nacido un nuevo concepto de red, el de "red activa", cuya idea fundamental consiste en introducir programabilidad a las redes para hacer posible que sus nodos puedan realizar procesamiento "a medida" de los paquetes que los atraviesan. ${ }^{48}$ A pesar de ello, la realidad es que en la actualidad nos encontramos en plena fase de incorporación de IPv6, situación que se prolongará durante los próximos años.

Es precisamente en esta coyuntura, de masiva expansión de la Internet fija, utilizando infraestructuras de redes de cable y de fibra óptica, y la progresiva implantación de IPv6, cuando aparece, además, un factor completamente nuevo y significativo: el desarrollo de la Internet móvil ("wireless Internet”), que caracterizará la $3^{\mathrm{a}}$ generación de Internet.

Pero este concepto no es simplemente la Internet fija llevada al terminal móvil, que no puede competir con el terminal fijo, sino la provisión de algunos servicios y aplicaciones basados en las facilidades combinadas, que ofrece el protocolo IPv6, y la movilidad propia de los terminales. Este aspecto puede satisfacer uno de los requisitos prioritarios de los SAT: su movilidad.

Muchos de los nuevos dispositivos que se conectarán a la red serán inalámbricos y móviles y podrán ser integrados en vehículos o transportados por los usuarios, que es la tendencia que lideran los teléfonos móviles, hasta tal punto, que se estima que, en tres años, el número de dispositivos móviles en la red será superior al de ordenadores que hay en la actualidad.

Queda pues muy claro que el gran impulsor de esta nueva generación de Internet, la tercera, será el mundo móvil. 
"Internet está experimentando una expansión tremenda. Dentro de veinte años se habrá convertido en algo ubicuo; en ella se integrarán dispositivos móviles y electrodomésticos. En 2006, existirán 2500 millones de dispositivos "online", y en 2010, la mitad de la población estará conectada, por lo que se hace necesario disponer de un mucho mayor número de direcciones." ${ }^{49}$

Esto ocurrirá cuando lleguen los sistemas móviles celulares de tercera generación, como el UMTS (Universal Mobile Telecommunication System), cuya operatividad está prevista a corto plazo. Y algo, además, sumamente importante y transcendental para las comunicaciones del futuro: son los servicios GMPCS (Global Movil Personal Communications Satellites). Se basán en constelaciones de satélites de baja y media altura, para ofrecer servicios de voz, fax, mensajería y vídeo, con cobertura mundial, que posibilitarán el acceso directo al satélite.

Son numerosos los proyectos y las alianzas puestas en marcha para crear también redes espaciales mediante constelaciones de satélites: Skybridge, Spaceway y Astrolink tienen previsto dar servicios en 1001, 1002 y 2003 respectivamente. Uno de ellos, Teledesic, ya está operativo, con una constelación de 288 LEOs y una cobertura de $195 \%$ del planeta, conocida como Internet-in-the-Sky. Entre los servicios que ofrece (telefonía, videoconferencia, etc.) se encuentra el acceso a Internet en banda ancha al mismo y único precio en el mundo.

Mientras tanto se está preparando la transición, ya que todo esto no sucederá de la noche a la mañana. De momento la denominada generación 2.5 de telefonía móvil: GPRS (General Packet Radio Service) y WAP (Wireless Application Protocol) están introduciendo la idea de terminal móvil permanentemente conectado a Internet. GPRS, además, está llevando el direccionamiento IP a GSM (Groupe Spécial Mobile), la $2^{\mathrm{a}} \mathrm{y}$ actual generación de telefonía móvil, que preconiza la futura red "todo IP".

No es de extrañar, ya que la tendencia del "ratio" usuario-direccionesIP se esté invirtiendo, gracias, entre otra razones, a la proliferación de los teléfonos móviles. En aproximadamente un año, la actual relación de 10:1 pasará a 1:1, y en un futuro no muy lejano se invertirá la proporción hasta 1:50. No hay que olvidar que las previsiones para la telefonía móvil, en 2004, son de 1.000 millones de abonados, y que la llamada Intenet Móvil tendrá alrededor de 400 millones de usuarios por esas mismas fechas. ${ }^{50}$ Será entonces cuando podremos ver los dispositivos "siempre conectados".

El proyecto I-Mode ${ }^{51}$ puesto en práctica por la operadora japonesa NTT DoCoMo, es la prueba evidente de que la convergencia UMTS ( $3^{\mathrm{a}}$ generación de móviles) y el protocolo Ipv6 son las bases tecnológicas de Internet $3 \mathrm{G}$, y que ésta es ya más que posible, es una realidad. 


\section{NOTAS}

${ }^{1}$ HAHN, H., (1994): Internet. Manual de referencia, Osborne/McGraw-Hill, Madrid, p. 20.

${ }^{2}$ Ibid., Introducción, pp. 19 y ss.

${ }^{3}$ Ordenadores dedicados a funciones específicas de dichos nodos, como por ejemplo conmutación, que en muchos casos sirven de puente entre las redes privadas e Internet.

${ }^{4}$ También denominado sistema final o "host", que pueden ser un simple ordenador personal o PC (Personal Computer), u otros dispositivos de tratamiento de in formación.

${ }^{5}$ Por ejemplo, líneas punto a punto, accesos FR (Frame Relay), etc.

${ }^{6}$ Citado en: LAQUEY, T. y RYDER, J., (1994): ¿Qué es Internet?, Addison-Wesley Iberoamericana, Wilmington (Delaware), U.S.A., p. 6.

${ }^{7}$ CERF, V. G., “¿Hacia dónde va Internet?”, Novatica: Internet Avanzado I, noviembrediciembre, 1996, p. 5.

${ }^{8}$ HUIDOBRO, J. M., "Evolución hacia la Tercera Generación de Comunicaciones Móviles", en: Comunicaciones World, n 152, enero, 2001, pp. 30-34.

${ }^{9}$ Revista LINK, Lucent Technologies, Bell Labs Innovations, Madrid, enero, 1999, p. 3. ${ }^{10}$ Ideada y diseñada por parte del belga Robert Cailliau y el británico Tim Bernes-Lee en el CERN (Laboratorio Europeo para Física de Partículas), un organismo multidisciplinario que controla las instalaciones atómicas de Europa, situado entre Suiza y Francia

${ }^{11}$ Otros servicios con mayor o menor aceptación son: NEWS (boletines de noticias); FTP (transferencia bidireccional de ficheros); TELNET (acceso remoto); IRC (conversaciones interactivas); etc.

${ }^{12}$ FEIJOO, C. y BLEDA, D., "Convergencia Audiovisual e Internet. Webcasting”, en: Revista $B I T, \mathrm{n}^{\circ} 111$, septiembre-octubre, 1998, pp. 26-34

${ }^{13}$ Sobre estos aspectos Fundesco editó, con la colaboración de la Dirección General de Comunicaciones y Enrique Bustamante, una colección de siete libros para el Plan Nacional de Formación y Difusión del Programa STAR. Y que aunque el programa ya ha finalizado, por lo poco que se ha avanzado al respecto en nuestro país, aun siguen vigentes: $1^{\circ}-\operatorname{Los}$ SAT y el desarrollo regional; $2^{\circ}$ - SAT para las pyme: acceso individual y compartido; $3^{\circ}$ Aplicaciones internacionales de los SAT, $4^{\circ}$ - Servicios de teletratamiento; $5^{\circ}$ - Servicios de información electrónica; $6^{\circ}$ - Servicios audiovisuales y móviles; $7^{\circ}$ - Servicios transacionales. Todos ellos en Madrid, 1990

${ }^{14}$ Hacia una economía europea dinámica. Libro verde sobre el desarrollo del mercado común de los servicios y equipos de telecomunicaciones, Oficina de Publicaciones Oficiales de las Comunidades Europeas, Bruselas, 1987, p. 45.

${ }^{15}$ Postal, Telegraph \& Telephone

${ }^{16}$ Los centros de conmutación se encargan de abrir el circuito, asignando esa capacidad en la fase de establecimiento, que se mantendrá hasta que los interlocutores decidan romper el circuito (desconexión).

${ }^{17}$ El Informe Nora-Minc dice textualmente: "Este neologismo se parece al empleado en Estados Unidos: 'compunication'. El hecho que el termino norteamericano ponga el acento en la informática -computar- y el nuestro en las telecomunicaciones, no es una casualidad. Expresa una relación de fuerzas, que, en Francia, está a favor de estas últimas". NORA, S. y MINC, A, (1980): La informatización de la sociedad, Fondo de Cultura Económica, México, p. 18. 
${ }^{18}$ Como la voz. La mayoría de las señales son de naturaleza analógica: imágenes, temperatura, etc.

${ }^{19}$ A diferencia de los datagramas que tienen un tratamiento individualizado en los nodos, todos los paquetes de un mismo mensaje tienen la misma dirección de destino. Y fueron las unidades de datos utilizadas en el primer protocolo de conmutación de paquetes: X.25.

${ }^{20}$ Un ejemplo podría ser el acceso de PCs para consultar bases de datos o servidores especializados.

${ }^{21}$ NORA, S. y MINC, A., op. cit., p. 18.

${ }^{22} \mathrm{El}$ espectro radioeléctrico en las redes de difusión de radio y TV; y el cable en redes telefónicas.

${ }^{23}$ La transmisión de 24 canales de voz analógicos requiere unos $96 \mathrm{Khz}$, ya que cada canal de voz necesita $4 \mathrm{Khz}$. Para transmitir esos mismos 24 canales en forma digital, con multiplexación por división temporal (MDT), se necesitan $776 \mathrm{Khz}$, es decir un ancho de banda 8 veces superior.

${ }^{24}$ La multiplexación es utilizada para enviar por un solo canal (agregado) varias señales que se transmiten simultáneamente por canales diferentes (tributarios) sin que se mezclen. Esta función la realizan los multiplexores y concentradores.

${ }^{25}$ CASAS, J. Ma.., "Hacia la normalización de las plataformas multimedia en el hogar", en: Actas del II Congreso nacional de ingenieros de telecomunicación, Madrid, 1998, pp. 87-92. ${ }^{26}$ La proximidad de los LEO consigue que el tiempo de ida y vuelta de una señal hasta la órbita sea de centésimas de segundo mientras que el sistema GEO requiere para la misma operación 0,24 segundos.

${ }^{27}$ Aunque también existen unos satélites con órbitas intermedias, aproximadamente unos $10.000 \mathrm{~km}$., tales como los MEO (Middle Earth Orbit) que aglutinan ventajas de los dos tipos definidos.

${ }^{28}$ Para cubrir todo el globo, el sistema LEO necesitará 20 veces más satélites que un sistema GEO y cinco veces más que la red de satélites de órbita media.

${ }^{29}$ Creada en 1957 por el Departamento de Defensa USA, para el desarrollo de tecnología militar.

${ }^{30}$ El primer diseño de ARPANET, fue publicado por Larry Roberts en 1967

${ }^{31}$ Una enumeración, secuenciada temporalmente, de los eventos que han ido construyendo, primero ARPANET y luego Internet, desde su nacimiento hasta hoy, así como datos y estadísticas de su crecimiento, se pueden encontrar en: ZAKON, R., "Hobbes' Internet Timeline v3.3", http://info.isoc.org/guest/zakon/Internet/ HistoryHIT.html, información obtenida el 3/06/98

${ }^{32}$ ARPANET se dio de baja y se desmanteló en marzo de 1990

${ }^{33}$ Una enumeración detallada de los eventos tecnológicos que han ayudado al desarrollo de Internet desde su creación hasta la actualidad, se pueden encontrar en: ZAKON, R., fuente citada

${ }^{34}$ Reconstruida en 1992, como Internet Arquitecture Board.

${ }^{35}$ En este contexto de dominios, se ha establecido un primer nivel o nivel raíz y distintos subdominios de segundo y tercer niveles. Los dominios de primer nivel pueden ser genéricos o geográficos. Entre los genéricos se encuentran com (organización comercial); edu (organización educativa.); gov (institución gubernamental); int (institución internacional); mil (organización militar); net (organización de red); org (organización 
sin ánimo de lucro). Los geográficos se asignan por países: es (España); fr (Francia); uk (Reino Unido); va (Vaticano).

${ }^{36}$ www.ietf.org

${ }^{37}$ www.isoc.org

${ }^{38}$ www.iana.org

39 "Las nuevas direcciones internet", en: Comunicaciones World", n 96, diciembre, 1995, pp. 35-36.

${ }^{40}$ El protocolo experimental Ipv5 se diseño para efectuar pruebas con los mecanismos de identificación de flujos (streaming) en tiempo real. Para evitar confusiones se optó por no utilizar esa denominación.

${ }^{41}$ LADID, L., "Hacia la Nueva Internet" en: "Ipv6. La Nueva Internet", suplemento especial de la revista Comunicaciones World, $\mathrm{n}^{\circ}$ 152, enero, 2001, pp. 6-7. Mas información en www.Ipv6Forum.com

${ }^{42}$ Se describen algunas de las más importantes de las que ya están definidas Pero ya se sabe que en el paradigma tecnológico actual "lo importante no es lo que la tecnología pueda hacer, sino lo que se pueda hacer con ella".

${ }^{43}$ DERN, D. P. y MACE, S., "Reinventar Internet", en revista BYT, febrero, 1998, pp. 51-57. ${ }^{44}$ GRADO CAFFARO, A \& M, "Internet2", en revista: Comunicaciones World, no 138 , octubre, 1999, pp. 40-42 . Mas información sobre Internet2 en: www:internet2.org

${ }^{45}$ GONZÁLEZ, J. L., CABALlERO, J. y SÁNCHEZ, Ma. S., "Mbone y la aportación del multicasting a los servicios multimedia en Internet", en: Novática. Internet Avanzado$I, \mathrm{n}^{\circ} 124$, noviembre-diciembre, 1996, pp. 38-49. Mas información en www.6Bone.net y www.6ren.net

${ }^{46}$ Denominación que se dio originariamente, y de forma temporal, a la nueva versión del protocolo IP, en el que se aumenta el campo de direcciones a 128 bits, y que finalmente pasó a denominarse IPv6

47 "Madrid global Ipv6 summit", en revista: Comunicaiones World, $\mathrm{n}^{\circ}$ 154, marzo, 2001, p. 76.

${ }^{48}$ Esto produce un cambio de paradigma de la red: los nodos, capaces de transportar exclusivamente octetos en forma pasiva, pasan a poder procesar los paquetes a cualquier nivel de la pila de protocolos.

${ }^{49}$ CERF, V., en Ibid

${ }^{50}$ GIL, E., "Móviles+Internet: el nuevo modelo de negocio", en: Comunicaciones World, $\mathrm{n}^{\mathrm{o}} 145$, mayo, 2000 , pp. 54-56

${ }^{51}$ www.nttdocomo.com 